\title{
The Impact of Motivation and Strategy Use on Course Outcome in Digital Learning Environment- A case Analysis of a Business School Course
}

\author{
Shadi Esnaashari \\ University of Auckland \\ S.Esnaashari@auckland.ac.nz
}

\author{
Lesley Gardner \\ University of Auckland \\ L.Gardner@auckland.ac.nz
}

\author{
Michael Rehm \\ University of Auckland \\ M.Rehm@auckland.ac.nz
}

\begin{abstract}
Using the Motivated Strategies for Learning Questionnaire (MSLQ) multiple times in an undergraduate business school course in a University in New Zealand, 188 students completed the questionnaire to explore how students' motivation and strategy use changed as they progressed and how these constructs predict students' course outcome. In contrast to other studies, our results showed varying levels of motivation as well as increasing strategy usage as the course progressed. Our exploratory analysis identified three subgroups within the class, each of which reported differently in terms of motivation and strategy use. From this analysis and course outcome data we infer how these finding may contribute to theory and classroom practice.
\end{abstract}

\section{Introduction}

One of the aims of teaching and learning is to produce lifelong learners who have the ability to take control of their learning and be self-regulated learners[1]. However, not all students are able to selfregulate their learning which has impacts on their course outcome [2]. There are some who struggle to meet the passing requirements for their courses. Studies from science instruction and schooling practices talk about reasons for students' inability to pass the course, it can be argued that such explanations, ignore one crucial aspect of the learning process which is motivation. Dabbagh [3] claims that technologically based tools help to enrich students' learning by developing students' self-regulatory skills. Dabbagh and Kitsantas [4] also suggested that by having various toolsets available, students could choose the most appropriate tool to support their learning. This will stimulate, self-regulate, and motivate learning. Based on self-regulated learning research (SRL) that looks at students as an active agent, who are responsible for their learning, students have their agency and decide for themselves whether to use the tool or not. Self-regulated learning has been identified as a factor affecting students' learning and achievement. While we do not deny the other reasons for students' inability to pass the course, as indicated in research, we argue that such explanations, ignore one crucial aspect of the learning process which is motivation. Therefore, we focus on the motivation of students in the classroom to understand the effect of all motivational components on the student outcome.

Prior research (e.g. Zusho, Pintrich and Coppola [5]) has investigated the motivational components in an educational context [6, 7]. However, these studies either used some of the MSLQ constructs [5] or for example, they did not look at the issue over time [8]. To the best of our knowledge, none of these studies to date has been conducted in a digital learning environment, and none have examined the effect of all students' motivational components on their performance over time in a new digital context. Therefore, to address the gaps, we are investigating all of MSLQ constructs over time in a digital context when the lecturer provided students with the variety of digital tools and left the students to choose them based on their level of motivation.

This study adopted Pintrich's (1991) model of motivation and cognition; the focus of this study was to find out how the motivation and strategy use of students changed over the course. And how these changes related to course outcome. In this paper, we investigated the motivation and strategy use through a self-report of students based on the role of students' motivation and strategies. We followed Pintrich and De Groot's work [9] to examine students' motivation and self-regulated learning in the classroom. We run this study with 188 Year 1 cohort of students in an academic department in a large-sized university in New Zealand. The data collection lasted for one semester of study. Students were selected because they were new to the tertiary education system and had no prior experience with audience participation tools.

Based on previous research [10], we expected to have a decline in motivation and strategy use over time. Moreover, we expected to see the use of organisation, elaboration, and self-regulatory strategies to cause higher course outcome [10]. Our analysis showed a decline in students' motivational levels as the course progressed toward the midterm and increased again as it got close to the end of the course. In contrast to other studies, students' use of strategies increased as the course progressed toward the midterm, and then it decreased as the course drew to a close. 
In our analysis of students' motivation and strategy use, we observed a large standard deviation among students, therefore, we further explored to see if we could find different groups and subgroups of students based on their level of motivation in the classroom [7, 11, 12]. Our analysis identified three subgroups of students. For this reason, we applied clustering as it is suggested by $[5,13]$ in order to understand the different subgroup of students.

The information regarding students' motivation, strategy use, groups and subgroups of students in the classroom helped us to understand why students are different and performing differently. The lecturer could find out about different motivational subgroups that existed in their class or may develop during their class. The lecturer could also help students by teaching them new strategies for their learning. As mentioned by Pintrich [14], examining motivational patterns is more beneficial compared to identifying the importance of single motivational constructs about other constructs. By understanding students' individual differences in terms of motivational level, the lecturers may be able to adapt their instruction so that they could help the individuals to change the motivational category of students. We can help to facilitate learning by increasing our understanding of the effects of motivation on performance. We can attempt increase students' motivation so that they set higher goals for themselves and help them approach the tasks with more confidence.

This paper is laid out as follows. We have outlined our research and its contribution to the field of instructional design in a digital learning environment. In the next sections, we review extant literature, our methods, findings, discussion, and conclusions.

\section{Literature Review}

There are different educational tools which have been used in the classroom environment to help students in their learning processes. The effectiveness of these tools in the educational setting is still understudied. Newby, Stepich, Lehman and Russell [15] mentioned that using technology in a learning environment had both advantages and disadvantages for motivation. They also mentioned about the effect of teaching methods in their study. Compeau, Correia and Thatcher [16] believed that for the last 30 years researchers have been using constructs such as perceived usefulness (PU) and perceived ease of use (PEOU) which were developed by Fred Davis in 1986. They mentioned that the constructs in the theories need to be revisited since technology integrated with people's life and novelty in technology did not have the same meaning. They discussed the value of self-efficacy in using technology and introduced a new concept in technology acceptance called computer self-efficacy by considering the implications of changing technologies and context.

Piccoli, Ahmad and Ives [17] introduced the virtual learning environment (VLE) concept that explains how digital context is different from the traditional classroom environment and also computer-aided instruction (CAI). Their framework is helpful for investigating VLE effectiveness. VLE creates a space where students are free from time and geographical constraints, which provides access to a wide array of resources. It facilitates communication and increases the interaction between the learners and instructors. The feeling regarding the effectiveness of the technology may affect changes between the digital context and traditional classroom environment. There is also another dimension in their framework called learner control. It considers the extent to which the learner controls instructional presentation [18].

There are studies which research the usefulness of technology tools on the performance of students [1922]. Or they showed that these technologies helped students by increasing the interaction between the instructor and students [20, 23]. Azevedo [24] showed that different tools have been used by students in different stages of self-regulated learning. However, the effectiveness of learning in a digital context is very much dependent on the students as well. Technology itself does not cause learning to occur. Hiltz [25] showed that motivated and mature students benefit more from a tool provided environment compared to less motivated and mature students. It is necessary for students to take control of their learning, evaluate their learning and apply changes in their learning strategies. These come from a self-regulated perspective. Selfregulated learning theory and motivation theory could explain how students would control their learning [26]. The self-regulated learning perspective regards student as an active agent who is responsible for their learning.

Although there is research on the users' intentions for accepting the tool use, little is known about the factors that affect adoption and use tools. There are different conditions which affect students' tool use. Winne's model of SRL considers five elements: conditions, operations, products, evaluations and standards (COPES) [27]. In this model, the students use tools, which could be cognitive, digital or physical in nature to operate on material objects (watching videos) to construct knowledge, and evaluate their own learning, e.g. by recalling the material in the quizzes (Winne et al., 2006). In the process of self-regulation, the students constantly evaluate their learning (quality of their recalls in the quizzes) and whether their choice of strategies are effective or not. This evaluation is based on how they recalled the materials (internal standard) or whether they could pass the course with passing grades (external 
standard). The effect of conditions (internal and external conditions) associated with the COPES model [28], when learners are using technology, has not been well studied. Internal conditions are motivation (selfefficacy, epistemic beliefs), goal-orientation, and prior knowledge (experience with tools), achievement, goal orientation, and cognitive load, and external conditions such as instructional design (grading of learners' selfassessments or sharing the self-assessments with peers), tasks mandating the use of a tool, previous learning history, and social context. These conditions have significant effects on the standards that students set for themselves and are used by them when they want to evaluate their learning [26, 29].

There are SRL researches that focuses on the motivation of the students [30, 31]. Demir and Yurdugül [32] identified motivation as a factor which had physical, cognitive and affective components on people's promotion to do things for e-learning. Winne and Hadwin [33] agree with Pintrich's ideas regarding motivational factors which affect students' behavioural, contextual and cognitive characteristics [34]. Pintrich [35] framework has been recognised as an important theoretical approach to understand the motivation. Several studies have looked at factors that affect students' success, focusing on students' motivation and use of learning strategies [36-38]. The Motivated Strategies for Learning Questionnaire (MSLQ) [36] is a self-report, measuring students' reported motivation and strategy use. It is measure reasons for engaging in a task (value component) and their beliefs about their own capacity to perform specific strategies and to control the learning situation (expectancy component) and their goal orientation (intrinsic and extrinsic goal orientation). In terms of strategy, it looks at the strategies that students report on their learning that include cognitive, metacognitive and resource management strategies. Cognitive and metacognitive strategy components include a) rehearsal, b) elaboration, c) organisation, d) critical thinking, and e) metacognitive self-regulation. Resource management strategies include a) time and study environment, b) effort regulation, c) peer learning, and d) help-seeking.

There are different studies that examined each of the elements separately. For example, Pintrich [39] demonstrated positive relations of task value beliefs and performance. Bandura, Freeman and Lightsey [40] showed that students who were capable of adequately completing a task, and believed in their abilities to do the task, achieved better at the end. Zeidner [41] showed a negative consequence of general worry and negative emotions on cognition and performance. Hilpert, Stempien, van der Hoeven Kraft and Husman [42] used 15 subscales of the MSLQ on students from introductory geoscience courses. They used confirmatory factor analysis to examine the latent factor structures described in previous MSLQ literature. Ayatollahi, Rasekh and Tavakoli [43] used MSLQ and applied SEM to investigate university students' beliefs about the nature of knowledge and how it affected reading ability via self-regulated learning strategies.

Bandura [44] notes that "perceived self-efficacy is not a measure of the skills one has but a belief about what one can do under different sets of conditions with whatever skills one possesses."

He believed that students who have the higher confidence and think they are capable of doing the task can achieve better compared to others who do not feel the same. In IS field, self-efficacy has been measured in two directions. Marakas, Johnson and Clay [45] measurements considered the underlying knowledge and users' skills. Compeau and Higgins [46] measurement considered more a sense of psychological confidence. They aimed at understanding of selfefficacy on individual computing technology. Learners' self-efficacy has been introduced to the other theories, for example, to the community of Inquiry by Shea and Bidjerano [47]. Fishbein and Ajzen [48] in the theory of reasoned action argued when individuals thought that computers would have positive benefits for them, then they would use them.

Zusho, Pintrich and Coppola [5] investigated how self-efficacy, task value, mastery goal orientation, performance goal orientation, interest, and anxiety from motivational construct and rehearsal, organization, elaboration, and metacognitive self-regulation from strategy use construct, changed over time and showed how these scales were related to the course outcome of the students. The authors studied the issue over time and clustered the students based on how they achieved in their course outcome to three groups of low, average, and high achievers. Braten and Olaussen [49] examined to find a different group of students in class based on mastery goal orientation, task value, self-efficacy, rehearsal, elaboration, and metacognitive strategies through clustering. Through longitudinal cluster analysis, they showed that even though the motivation of students dropped as the course progressed, most of the students could maintain their motivation.

Saadé, He and Kira [50] studied the relationship between motivation and performance in an online learning environment. They investigated the factors that contributed to the success or failure of students. They examined students' attitude, affect, motivation, and perception of online learning tool usage. The study showed that effect and perception had strong measurement capabilities with the adopted items while motivation was measured the weakest. These contradictory results emphasised the importance of researching motivation for blended learning as students 
needed to be highly motivated to complete preparation prior to coming to class.

Motivational studies took a social cognitive perspective by focusing on the role of students' beliefs and strategies. Theories of motivation also looked at motivation as a process and not just a product. Therefore, in this study, we look at motivation through students' reports of their beliefs over time to consider the process of motivational change. We are fortunate to have access to a significant amount of data regarding students' engagement in class activities and their final outcomes at the end of the course. In addition, using all the constructs from MSLQ, our study examined the motivation over time in a digital context using MSLQ. Motivation has been considered as a process by collecting students' motivation three times in the course. This is discussed next.

\section{Methods}

This study is part of a larger mix method study, the structure of which is shown in Figure 1. Participants in this study were 188 first-year students from a high ranking University in New Zealand in 2018. The first year students were chosen because we would like to explore the issue with fresh students. The lecturer used the tools for the last five years and had a positive attitude towards technology. This was a blended learning course which was run for 12 weeks. The core material was available on the course web page, and review sessions were conducted for discussion purposes. The students were required to watch all the videos and participate in the quizzes at the end of videos before coming to the review sessions. There was a review session conducted weekly for students. Students had the option of going to class in person or watch the review session online when it was streaming and participate in the review quizzes run by the lecturer in class. The lecturer used an audience participation tool in class to engage the students in class activities and running tournaments in the class. The students needed to beat other peers through using the audience participation tool in class so that their name appeared on the leaderboard. The students had access to Piazza (Students' forum) in case they needed to clarify anything among themselves or with their lecturer.

For understanding the motivation of students, we used Motivated Strategies for Learning Questionnaire MSLQ. MSLQ is a questionnaire developed by Pintrich, Smith, Garcia and McKeachie [37] to measure cognitive strategies, metacognitive strategies, and resource management through 31 items in the motivation section and 50 items in the learning strategies section. MSLQ is an instrument used to measure the motivational orientations and different learning strategies that students use. MSLQ follows a cognitive perspective when students' beliefs and cognition are the instructional input for being an active processor of information in class.

12 weeks of study

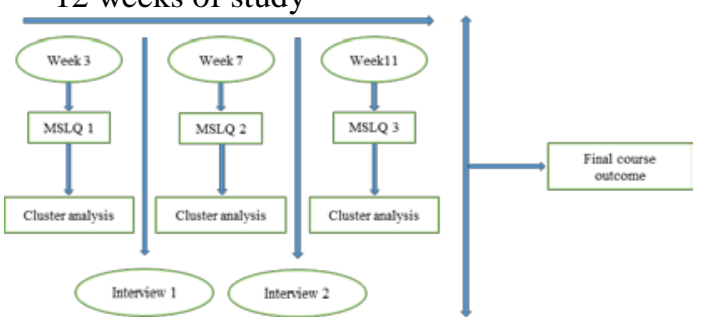

Figure 1: Structure of our study 12 weeks of study

Student grades were also collected at the end of the semester as a measure of student course outcome. Using MSLQ to gather quantitative data we examined student motivation as a factor that would affect students' selfregulated learning. We asked about the students' attitude and belief in the self-reported survey. Through the survey [36], we measured students' reported cognitive strategy use (e.g., rehearsal, organization strategies, and elaboration), their reported selfregulation (e.g., cognitive engagement, time, place and effort regulation), their reasons for engaging in a task (value component) and their beliefs about their own capacity to perform specific strategies and to control the learning situation (expectancy component). As shown in Figure 1, we ran MSLQ, three times in Week 3, Week 7 , and Week 11 of a 12 week semester. In our full study we aim to understand students' perception regarding tool use, based on how students responded to MSLQ, we clustered the students into four and interviewed three students from each cluster. Our aim was to interview students from different motivational groups. In total, we interviewed 12 students twice in the course (in total 24 interviews and each interview lasted approximately 30 minutes). We interviewed the students twice so that we could remove the effect of technology novelty that we might have been present in the first interview. Through our analysis of students' motivation and strategy use, we observed large standard deviation among students, therefore, we further explored this data to see if we could find different groups and subgroups of students based on their level of motivation in the classroom by applying clustering technique.

\section{Analysis}

In this section, we discussed the evidence discovered from running the MSLQ questionnaire three times in the course, the summary of which is illustrated in Table 1. Table 1 shows the mean and standard deviation for all the constructs. We investigated how the students' motivation and strategy use changed over the course by 
comparing the descriptive analysis of each construct across the three iterations of MSLQ. This analysis was based on how students judged their motivation and strategy use. Then we calculated the value, expectancy, affective, cognitive and metacognitive, and resource management strategy components, and compared the descriptive analysis of the components.

In terms of value component, students' two-goal orientation scales decreased as the course progressed. However, task value decreased until midterm, and then again it increased for the third round. In terms of expectancy component, control belief and self-efficacy for learning and performance decreased as the course progressed for round two and three. In terms of affective component, test anxiety decreased in the second round and it increased again in the third round. In terms of cognitive and metacognitive strategies, rehearsal, elaboration, metacognitive self-regulation increased as the course progressed in both rounds two and three. Critical thinking increased in the second round and stayed the same in the third time. Organisation decreased in the second round and increased in the third round. In terms of resource management, time and study environment and effort regulation decreased for both second and third rounds. Peer learning and help-seeking decreased in the second round and increased in the third round.

In the second phase of our analysis, we looked at the scales under motivation and strategy use constructs. Table 2 shows the descriptive statistics of the scales. As seen, the value and affective components decreased in the second round and they increased again in the third round. Expectancy and resource management decreased in the second and third rounds. The cognitive and metacognitive strategy is the only scale that increased as the course progressed in the second and third rounds. The change in the scales for the second round could be explained because the students had gone for an exam before running the second round of MSLQ.

In the third phase of our analysis, we looked at the motivation and strategy constructs through students' reports. The descriptive analysis is shown in Table 3. The data showed that motivation decreased in the second round and increased in the third round. The data also showed that students' use of strategies increased in the second round, and then it decreased in the third round.

Our results were different from the results reported by Zusho, Pintrich and Coppola [5]. Zusho, Pintrich and Coppola [5] presented the means and standard deviations of students' cognitive strategy use at the twotime points. They reported that students' levels of motivation decreased over time. They also showed that there was a decline in students' level of self-efficacy and Task value. They also showed that there were no significant differences in students' interest and anxiety over time. They showed a significant decline in students' reported use of rehearsal and elaborative strategies, while students' use of organisational and metacognitive strategies increased from the second round to the third round

\section{Table 1. Descriptive statistics of MSLQ's scales over time}

\begin{tabular}{|c|c|c|c|c|c|c|}
\hline & \multicolumn{2}{|c|}{ Time 1} & \multicolumn{2}{|l|}{ Time 2} & \multicolumn{2}{|l|}{ Time 3} \\
\hline & Mean & SD & Mean & SD & Mean & SD \\
\hline Intrinsic goal orientation & 4.71 & .85 & 4.55 & .89 & 4.52 & 1.00 \\
\hline Extrinsic goal orientation & 5.40 & 1.08 & 5.11 & 1.10 & 5.10 & 1.11 \\
\hline Task Value & 5.32 & 1.00 & 4.28 & .81 & 5.10 & 1.03 \\
\hline Control Beliefs & 5.16 & .86 & 5.14 & .81 & 5.05 & .916 \\
\hline $\begin{array}{l}\text { Self-efficacy for Learning and } \\
\text { Performance }\end{array}$ & 4.96 & .88 & 4.89 & .91 & 4.84 & .99 \\
\hline Test Anxiety & 4.64 & 1.13 & 4.50 & 1.14 & 4.60 & 1.22 \\
\hline Rehearsal & 4.43 & 1.02 & 4.67 & 1.03 & 4.77 & 1.05 \\
\hline Elaboration & 4.58 & .83 & 4.60 & .94 & 4.71 & .95 \\
\hline Organization & 4.88 & .84 & 4.72 & .90 & 4.82 & .93 \\
\hline Critical Thinking & 3.84 & 1.03 & 3.91 & .96 & 3.91 & 1.15 \\
\hline Metacognitive self-regulation & 4.30 & .69 & 4.38 & .71 & 4.42 & .74 \\
\hline Time and Study Environment & 4.82 & .78 & 4.70 & .85 & 4.60 & .87 \\
\hline Effort regulation & 4.85 & 1.06 & 4.72 & 1.04 & 3.72 & .84 \\
\hline Peer learning & 3.42 & 1.34 & 3.33 & 1.40 & 3.59 & 1.42 \\
\hline Help Seeking & 3.24 & 1.21 & 3.20 & 1.24 & 3.33 & 1.30 \\
\hline
\end{tabular}

The large standard deviation in our study showed that there were different groups of students. Thus, in order to understand how students' level of motivation and strategy use were different among the students, we divided our sample data into three categories of high achieving students, average achieving students, and low-achieving students as suggested by [5]. The results of categorizing students are illustrated in Table 4.

Table 2. Descriptive statistics of MSLQ'S constructs over time

\begin{tabular}{|l|l|l|l|l|l|l|}
\hline & \multicolumn{2}{l|}{ Time 1 } & \multicolumn{2}{l|}{ Time 2 } & \multicolumn{2}{l|}{ Time 3 } \\
\hline & Mean & SD & Mean & SD & Mean & SD \\
\hline Value Components & 15.43 & 2.25 & 13.95 & 2.19 & 14.71 & 2.59 \\
\hline Expectancy Components & 10.13 & 1.49 & 10.03 & 1.49 & 9.88 & 1.69 \\
\hline Affective Components & 4.65 & 1.14 & 4.51 & 1.14 & 4.60 & 1.22 \\
\hline Cognitive and & 21.93 & 3.41 & 22.29 & 3.47 & 22.64 & 3.72 \\
Metacognitive Strategies & & & & & & \\
\hline Resource Management & 16.25 & 2.78 & 15.95 & 2.86 & 15.25 & 2.87 \\
Strategies & & & & & & \\
\hline
\end{tabular}


For high achievers, the value component decreased in the second round and increased in the third round. Expectancy component increased in the second round and decreased in the third round. Affective components decreased as the course progressed in the second and third rounds.

Table 3: Descriptive statistics of motivation and strategy use

\begin{tabular}{|l|l|l|l|l|l|l|}
\hline & & & & & & \\
\hline & Mean & SD & Mean & SD & Mean & SD \\
\hline Motivation & 30.22 & 3.70 & 28.49 & 3.61 & 29.20 & 4.37 \\
\hline & & & & & & \\
Strategy & 38.18 & 5.36 & 38.23 & 5.48 & 37.89 & 5.75 \\
\hline
\end{tabular}

For this group, the results showed that the level of anxiety decreased as the course progressed and it affected their performance. Cognitive and metacognitive strategy use increased in the second round and decreased in the third round. However, resource management strategies increased as the course progressed in the second and third rounds.

Table 4. Cluster analysis of students based on their level of motivation and strategy use

\begin{tabular}{|l|l|l|l|}
\hline & Cluster & Cluster & Cluster \\
\hline MSLQ Components & 1 & 2 & 3 \\
\hline Value Components1 & 11.00 & 20.17 & 11.50 \\
\hline Expectancy Components1 & 9.13 & 12.00 & 11.63 \\
\hline Affective Components1 & 4.40 & 6.40 & 4.60 \\
\hline Cognitive and Metacognitive Strategies1 & 16.80 & 20.43 & 19.50 \\
\hline Resource Management Strategies1 & 13.50 & 17.29 & 11.92 \\
\hline Value Components2 & 8.83 & 17.92 & 9.92 \\
\hline Expectancy Components2 & 9.13 & 12.88 & 12.38 \\
\hline Affective Components2 & 3.80 & 6.00 & 2.00 \\
\hline Cognitive and Metacognitive Strategies2 & 16.57 & 29.35 & 13.85 \\
\hline Resource Management Strategies2 & 11.46 & 20.46 & 6.88 \\
\hline Value Components3 & 6.00 & 19.25 & 10.33 \\
\hline Expectancy Components3 & 8.63 & 12.25 & 12.00 \\
\hline Affective Components3 & 3.80 & 5.60 & 1.20 \\
\hline Cognitive and Metacognitive Strategies3 & 16.83 & 29.00 & 18.38 \\
\hline Resource Management Strategies3 & 10.07 & 20.78 & 8.93 \\
\hline Final Score & 13.66 & 47.82 & 43.39 \\
\hline
\end{tabular}

For moderate achievers, the value component decreased in the second round and increased in the third round. Expectancy component increased in the second round and decreased in the third round. Affective component decreased as the course progressed in the second and third rounds. Cognitive and metacognitive strategies decreased in the second round and increased in the third round. Resource management decreased in the second and increased in the third rounds.

For low achievers, value components decreased in the second and third rounds. Expectancy component remained the same in the second and decreased in the third rounds. Affective component decreased in the second round and stayed the same in the third round. Cognitive and metacognitive strategies decreased in the second round and increased in the third round. Resource management decreased as the course progressed in the second and third rounds.

High and moderate achievers had the same trends for value, expectancy and affective components. However, high achievers' level of strategy use increased in the second round. However, the cognitive strategy use decreased. As we observed, the value component for both high and moderate achievers decreased in the second round and increased in the third round. However, for the low achievers, value component decreased in both rounds. Expectancy component increased in the second round and decreased in the third for both high achievers and moderate achievers. For low achievers, expectancy remained the same in the second and decreased in the third round. Even affective component had the same trend for high and moderate achievers. However, for high achievers, cognitive and metacognitive strategy use, increased in the second round and decreased in the third round. For moderate and low achievers, cognitive and metacognitive strategy use decreased in the second round and increased in the third round. For high achievers, level of resource management increased in both second and third rounds. The level of resource management for moderate achievers decreased in the second round and increased in the third round. Level of resource management for low achievers decreased in both second and third rounds.

Cluster 2 students who were the higher achievers had the highest value in all the components such as value, expectancy, affective, cognitive and metacognitive strategies, and resource management. Cluster 3 students who were the moderate achievers had the second highest value in all the constructs except they had the lowest value in resource management strategies in the first round, affective component in the second round, cognitive and metacognitive strategies, resource management strategies in the second round, affective component in the third round, and resource management strategies in the third round. Cluster 1 students who were the lowest achievers had the minimum amount of value in all the constructs except resource management strategies in the first round, affective component in the second round, cognitive and metacognitive strategies, 
resource management strategies in the second round, affective component in the third round, and resource management strategies in the third round. Even though in most of the strategy scales, Cluster 3 students had a lower amount of value compared to Cluster 1 students, though they still got moderate results.

Previous studies in terms of the relations between motivation and cognitive strategy use showed that students who had higher levels of self-efficacy, task value, and mastery goals used deeper- cognitive strategies such as elaboration and metacognition.

Figure 2 shows how different groups of students were different in terms of all MSLQ scales. Cluster 2 students who got the highest scores at the end had the maximum value in all measures. For Cluster 3 students who had the second highest scores in class after Cluster 2 students, most of the constructs were higher than those of Cluster 1 students, except the second round of component 2 plus the affective and resource management component in their third round.

\section{Three clusters across the scales}

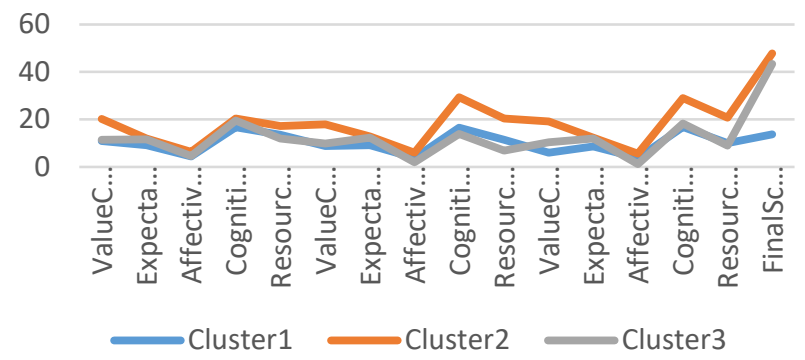

Figure 2. Ratings of each group of students' reports on MSLQ constructs by performance

\section{Discussion}

In this study, we examined how the level of motivation and strategy use changed as the course progressed and how each of the constructs was related to the course outcome in a Business school course. We were motivated to look at motivation as both theory and practice identified it as an important factor in the learning of students. In this study, the lecturer observed high dropouts rate in his course. As the literature suggested using educational tools in class, he started to use them in his class and converted his method of teaching to a more blended learning course. What he observed was that not all the students used the tools as he expected. Therefore, he reckoned, some students could pass the course, and some were not able to pass.

In his method of teaching, he aimed to produce lifelong learners who could regulate their learning.
Based on self-regulated learning, an internal condition such as motivation affects the outcome of the students. Based on these, we started to measure the motivation and strategy use of the students. To understand motivation, we followed Pintrich's framework. We used MSLQ and ran it three times. There were studies that looked at motivation. They either measured motivation once or twice but did not measure all the motivational constructs. For example, they started to measure the motivation from halfway through the course which did not tell us what happened from the beginning of the course to mid-term.

Thus, we measured all the scales under motivation and strategy use three times in the course and looked at how students' motivation and strategy use changed as the course progressed. Parts of our analysis were consistent with previous studies and some were not. We understood the average of students' level of motivation decreased in the second measurement, and it increased again in the third one. Level of the strategy use increased in the second round and decreased in the third round. Other studies such as [5] documented how students' level of motivation decreased but our study showed that even though we observed a decline in motivation, it started to increase again as the course progressed towards the end of the course.

We then looked at each of the components under motivation and strategy use for the whole class. In terms of value component, students' two-goal orientation scales decreased as the course progressed. However, task value decreased until midterm, and then again it increased in the third round. In terms of expectancy component, control belief and self-efficacy in learning and performance also decreased as the course progressed for both measure two and three. In terms of affective component, test anxiety decreased for the second round and increased again for the third round. In terms of cognitive and metacognitive strategies, in rounds two and three rehearsal, elaboration, metacognitive self-regulation increased as the course progressed. Critical thinking increased in the second round and stayed the same in the third round. Organisation decreased in the second round and increased in the third round. In terms of resource management, time and study environment and effort regulation decreased in both second and third rounds. Peer learning and help-seeking decreased in the second round and increased in the third round.

Through calculating the standard deviation, we observed spread in the students' motivation and strategy use. We identified that there existed different subgroups among different groups in class. We used clustering as it is suggested by Magnusson and Stattin [13] as the best way to understanding individual development over time. Based on what was suggested by Zusho, Pintrich 
and Coppola [5], we grouped the students into three based on their level of motivation and strategy use. We also compared the students based on how they reported about their motivation and strategy use constructs.

High and moderate achievers had the same trends in value, expectancy and affective components. However, high achievers' level of strategy use increased in the second round. However the cognitive strategy use decreased. As we observed, the value component in both high and moderate achievers decreased in the second round and increased in the third round. However, for the low achievers, value component decreased in both rounds. Expectancy component increased in the second round and decreased in the third round among both high achievers and moderate achievers. For low achievers, expectancy remains the same in the second and decreased in the third round. Even affective component had the same trend for high and moderate achievers. However, for high achievers, cognitive and metacognitive strategy use increased in the second round and decreased in the third round. For moderate and low achievers, cognitive and metacognitive strategy use decreased in the second round and increased in the third round. For high achievers, level of resource management increased in both second and third rounds. The level of resource management for moderate achievers decreased in the second round and increased in the third round. Level of resource management in low achievers decreased in both second and third rounds. We found out that it was not enough to find the effective components and that we needed to improve them among the students. When expectancy was high for high achievers, we understood that we needed to increase the level of expectancy among the students. We also understood rehearsal, had an effect on course outcome, so we needed to teach new strategies to the students.

This study hade several implications. We understood that motivational beliefs were very important in students' achievement. We observed that students who could maintain self-efficacy levels achieved better. Therefore, we could convey to the students that the Business course was learnable. And then through teaching strategies, we could help them to achieve better. The lecturer could also asked students to share their knowledge and learning strategies. The lecturer could explain the task value and mention it in the instructional design and though that he could increase the awareness of students. The lecturer also tried to show the application of the content in real life to help the students understand the task value better.

The information regarding students' motivation, strategy use, groups and subgroups of students in the classroom not only helped with the theory building but also it was significant with educational practice. It helped us to understand why students were different and why they were performing differently. The lecturer could find out about different motivational subgroups that existed in their class or may develop during their class. The lecturer could also help students by teaching them new strategies for their learning.

The lecturer provided mini revision lectures and ran a tournament in class based on the questions that most of students got wrong. In this way he revisited the material that most of them had difficulty understanding. Students also mentioned that they used these quizzes as a self-evaluation tool and based on how they performed in the quizzes, they made changes to their strategies. For example, they wrote more notes or stopped doing parallel stuff while they were watching videos. As mentioned by Pintrich [14], examining motivational patterns was more beneficial compared to identifying the importance of single motivational constructs about other constructs. By understanding students' individual differences in terms of motivational level, the lecturers may be able to adapt their instruction so that they could help the individuals to change the motivational category of students. We could help to facilitate learning by increasing our understanding of the effects of motivation on performance. We could also increase students' motivation so that they set higher goals for themselves to approach the tasks with more confidence.

\section{Conclusion and future study}

We investigated motivation and self-regulated learning by running MSLQ three times in a course. The quantitative survey helped us to measure separate constructs. We ran the questionnaire three times to see how the motivation of students changed. We collected data from 188 students in the Business school at a university in New Zealand. We compared the components across the three surveys. Students' motivation components decreased in the second measure and increased in the third measure. The decrease in motivation was also well documented by Zusho, Pintrich and Coppola [5]. Our findings showed that motivation decreased until mid-semester which is consistent with other studies in the literature, but it increased again after midterm. In between, students took their test and received feedback which could affect their reported data. We intended to see in our future study how low achievers and high achievers were different in terms of their motivation. We found that as the course progressed, students' judgments of their confidence to do well in the class and task importance also decreased in the second survey in the middle of the course and increased in the final survey at the end of the course. Task importance incline also showed that students, as the course progressed, believed the tools were more important in their learning. This finding was consistent 
with our qualitative data in which students believed that the tools were more important as the course progressed. In terms of strategy use, students' strategy use increased as the course progressed except for the organisation component which decreased in the second and third rounds. Our finding regarding students' strategy use was in contrast to those of other studies [e.g. 5]. A study run by Zusho et al. [7] showed a decrease in the students' strategy use. When we analyzed our data, we identified differences among students in terms of their level of motivation and strategy use. We identified three groups of students; high, moderate, and low achievers. We compared these groups with each other based on how they reported in three rounds of MSLQ. Our study like all others had limitations. In our study, we just looked at the motivation and strategy use of students. However, there are other internal and external conditions or characteristics such as age, gender, or ethnicity which we did not consider in our study [51]. In our future study, we will relate the motivation and cognitive components to the student final course outcome. We intend to understand the components which affect the performance. We know that it is not enough to understand which components have affected the performance but we also need to understand how we can improve those features, for example, self-efficacy and task value among the students, or, for example, teach students how to employ new strategies so that they can achieve better. In our study, we observe changes in their motivation, but in our future study, we need to see how we can moderate the students' motivation in the process through changes in the classroom context. Therefore, we will also look at students from different motivational groups and will investigate how their beliefs are different in terms of their self-efficacy, effort control, and strategy use. We have identified a model based on what they report and what they get at the end of the course. In our future study, we would like to test our theory by using Structural Equational Modeling. In our future study, we will explore the relation between students' motivation and their activities. It would be interesting to observe if how they behave is what they actually report about themselves.

\section{References}

[1] P. C. Candy, R. G. Crebert, and J. O'leary, Developing lifelong learners through undergraduate education: Australian Government Pub. Service, 1994.

[2] S. Dawson, S. Joksimović, V. Kovanović, D. Gašević, and G. Siemens, "Recognising learner autonomy: Lessons and reflections from a joint x/c MOOC," Proceedings of Higher Education Research and Development Society of Australia 2015, 2015.
[3] N. Dabbagh, "Using a web-based course management tool to support face-to-face instruction," The Technology Source, no. 12, pp. 32-51, 2002.

[4] N. Dabbagh, and A. Kitsantas, "Using web-based pedagogical tools as scaffolds for self-regulated learning," Instructional Science, vol. 33, no. 5, pp. 513-540, 2005.

[5] A. Zusho, P. R. Pintrich, and B. Coppola, "Skill and will: The role of motivation and cognition in the learning of college chemistry," International journal of science education, vol. 25, no. 9, pp. 1081-1094, 2003.

[6] K. McKenzie, K. Gow, and R. Schweitzer, "Exploring first-year academic achievement through structural equation modelling," Higher Education Research \& Development, vol. 23, no. 1, pp. 95-112, 2004.

[7] S. Heirweg, M. De Smul, G. Devos, and H. Van Keer, "Profiling upper primary school students' self-regulated learning through self-report questionnaires and think-aloud protocol analysis,” Learning and Individual Differences, vol. 70, pp. 155-168, 2019.

[8] H. Bembenutty, "Sustaining motivation and academic goals: The role of academic delay of gratification," Learning and individual differences, vol. 11, no. 3, pp. 233257, 1999.

[9] P. R. Pintrich, and E. V. De Groot, "Motivational and self-regulated learning components of classroom academic performance," Journal of educational psychology, vol. 82, no. 1, pp. 33, 1990.

[10] P. R. Pintrich, and D. H. Schunk, Motivation in education: Theory, research, and applications: Prentice Hall, 2002.

[11] B. Regueiro, J. C. Núñez, A. Valle, I. Piñeiro, S. Rodríguez, and P. Rosário, "Motivational profiles in high school students: Differences in behavioural and emotional homework engagement and academic achievement," International Journal of Psychology, vol. 53, no. 6, pp. 449457, 2018.

[12] L. Linnenbrink-Garcia, S. V. Wormington, K. E. Snyder, J. Riggsbee, T. Perez, A. Ben-Eliyahu, and N. E. Hill, "Multiple pathways to success: An examination of integrative motivational profiles among upper elementary and college students,” Journal of educational psychology, vol. 110, no. 7, pp. 1026, 2018.

[13] D. Magnusson, and H. Stattin, Person-context interaction theories: Department of Psychology, University of Stockholm, 1996.

[14] P. R. Pintrich, "A motivational science perspective on the role of student motivation in learning and teaching contexts," Journal of educational Psychology, vol. 95, no. 4, pp. 667, 2003.

[15] T. Newby, D. Stepich, J. Lehman, and J. Russell, "Instructional technology for teaching and learning: Designing instruction, integrating computers, and using media," Educational Technology \& Society, vol. 3, no. 2, pp. 106-107, 2000.

[16] D. R. Compeau, J. Correia, and J. Thatcher, "Implications of Technological Progress for the Measurement of Technology Acceptance Variables: The Case of Selfefficacy,” 2017.

[17] G. Piccoli, R. Ahmad, and B. Ives, "Web-based virtual learning environments: A research framework and a 
preliminary assessment of effectiveness in basic IT skills training,” MIS quarterly, pp. 401-426, 2001.

[18] R. L. Newkirk, "A comparison of learner control and machine control strategies for computer-assisted instruction," Programmed Learning and Educational Technology, vol. 10, no. 2, pp. 82-91, 1973.

[19] M. Alavi, "Computer-mediated collaborative learning: An empirical evaluation,” MIS quarterly, pp. 159174, 1994.

[20] S. R. Hiltz, "Teaching in a virtual classroom," International Journal of Educational Telecommunications, vol. 1, no. 2, pp. 185-198, 1995.

[21] S. Esnaashari, L. Gardner, and M. Rehm, "Educational Technology Tools: Longitudinal Views of Students," 2019.

[22] S. Esnaashari, L. Gardner, and M. Rehm, "Students' perceptions of using technology in flipped classrooms environment." pp. 190-199.

[23] J. G. Schutte, Virtual Teaching in Higher Education: The New Intellectual Superhighway Or Just Another Traffic Jam?: Jerald G. Schutte., 1997.

[24] R. Azevedo, "Computer environments as metacognitive tools for enhancing learning," Educational Psychologist, vol. 40, no. 4, pp. 193-197, 2005.

[25] S. R. Hiltz, The virtual classroom: Learning without limits via computer networks: Intellect Books, 1994.

[26] P. H. Winne, "How software technologies can improve research on learning and bolster school reform," Educational Psychologist, vol. 41, no. 1, pp. 5-17, 2006.

[27] P. H. Winne, "Experimenting to bootstrap selfregulated learning,” Journal of educational Psychology, vol. 89, no. 3, pp. 397, 1997.

[28] P. H. Winne, and A. F. Hadwin, "Studying as selfregulated learning," Metacognition in educational theory and practice, vol. 93, pp. 27-30, 1998.

[29] P. H. Winne, "A metacognitive view of individual differences in self-regulated learning," Learning and individual differences, vol. 8, no. 4, pp. 327-353, 1996.

[30] M. Credé, and L. A. Phillips, "A meta-analytic review of the Motivated Strategies for Learning Questionnaire,” Learning and Individual Differences, vol. 21, no. 4, pp. 337-346, 2011.

[31] B. J. Zimmerman, and M. Martinez-Pons, "Construct validation of a strategy model of student selfregulated learning,” Journal of educational psychology, vol. 80, no. 3, pp. 284, 1988.

[32] Ö. Demir, and H. Yurdugül, "Investigation Of Effect Of E-Learning Readiness Levels Of Academic Staff On Those Of Universities,” 2015.

[33] P. H. Winne, and A. F. Hadwin, "The weave of motivation and self-regulated learning," Motivation and selfregulated learning: Theory, research, and applications, no. 2, pp. 297-314, 2008.

[34] P. R. Pintrich, "The role of goal orientation in selfregulated learning,” Handbook of self-regulation, vol. 451, pp. 451-502, 2000.

[35] P. R. Pintrich, "An achievement goal theory perspective on issues in motivation terminology, theory, and research," Contemporary educational psychology, vol. 25, no. 1, pp. 92-104, 2000.
[36] P. R. Pintrich, "A manual for the use of the Motivated Strategies for Learning Questionnaire (MSLQ),” 1991.

[37] P. R. Pintrich, D. A. Smith, T. Garcia, and W. J. McKeachie, "Reliability and predictive validity of the Motivated Strategies for Learning Questionnaire (MSLQ)," Educational and psychological measurement, vol. 53, no. 3, pp. 801-813, 1993.

[38] B. J. Zimmerman, and M. Martinez-Pons, "Student differences in self-regulated learning: Relating grade, sex, and giftedness to self-efficacy and strategy use," Journal of educational Psychology, vol. 82, no. 1, pp. 51, 1990.

[39] Pintrich, "The role of motivation in promoting and sustaining self-regulated learning," International journal of educational research, vol. 31, no. 6, pp. 459-470, 1999.

[40] A. Bandura, W. Freeman, and R. Lightsey, "Selfefficacy: The exercise of control," Springer, 1999.

[41] M. Zeidner, "Adaptive coping with test situations: A review of the literature,” Educational Psychologist, vol. 30, no. 3, pp. 123-133, 1995.

[42] J. C. Hilpert, J. Stempien, K. J. van der Hoeven Kraft, and J. Husman, "Evidence for the latent factor structure of the MSLQ: A new conceptualization of an established questionnaire," SAGE open, vol. 3, no. 4, pp. $2158244013510305,2013$.

[43] M. A. Ayatollahi, A. E. Rasekh, and M. Tavakoli, "Learner beliefs, self-regulated learning strategies and 12 academic reading comprehension: A structural equation modeling analysis,” World Applied Sciences Journal, vol. 17, no. 1 , pp. 36-49, 2012

[44] A. Bandura, "Self-efficacy: toward a unifying theory of behavioral change,” Psychological review, vol. 84, no. 2, pp. 191, 1977.

[45] G. Marakas, R. Johnson, and P. F. Clay, "The evolving nature of the computer self-efficacy construct: An empirical investigation of measurement construction, validity, reliability and stability over time," Journal of the Association for Information Systems, vol. 8, no. 1, pp. 2, 2007.

[46] D. R. Compeau, and C. A. Higgins, "Computer selfefficacy: Development of a measure and initial test,” MIS quarterly, pp. 189-211, 1995.

[47] P. Shea, and T. Bidjerano, "Learning presence: Towards a theory of self-efficacy, self-regulation, and the development of a communities of inquiry in online and blended learning environments," Computers \& Education, vol. 55, no. 4, pp. 1721-1731, 2010.

[48] M. Fishbein, and I. Ajzen, "Belief, attitude, intention, and behavior: An introduction to theory and research,” 1977.

[49] I. Braten, and B. S. Olaussen, "Profiling individual differences in student motivation: A longitudinal clusteranalytic study in different academic contexts," Contemporary Educational Psychology, vol. 30, no. 3, pp. 359-396, 2005.

[50] R. G. Saadé, X. He, and D. Kira, "Exploring dimensions to online learning," Computers in human behavior, vol. 23, no. 4, pp. 1721-1739, 2007.

[51] E. Panadero, "A Review of Self-regulated Learning: Six Models and Four Directions for Research," Frontiers in Psychology, vol. 8, 2017. 
Page 99 